\title{
Teodoro, A. (2020). Contesting the Global Development of Sustainable and Inclusive Education. Education Reform and the Challenges of Neoliberal Globalization. New York and London: Routledge.
}

A recensão crítica, que me propus realizar e que aqui apresento, assume-se, em certa medida, como um exercício hermenêutico, como um processo que, simultaneamente, leva o leitor a adentrar-se na obra de António Teodoro, mas que por si só, desvela possibilidades várias de outros conhecimentos, de ligações e redes com outros conceitos, também eles capazes de se assumirem como parte deste debate que destaca a política educativa e as suas reformas num contexto de globalização neoliberal.

Este texto, sendo um exercício crítico de interpretação, não é neutro nem tão-pouco inocente. É uma possível "leitura da palavra", parafraseando P. Freire. É um texto que surge naturalmente marcado pelas minhas vivências pessoais, mas, sobretudo, académicas e científicas que estruturam a minha "leitura do mundo", das quais fazem parte o autor da obra agora em análise, de quem fui aluno e orientando aquando a realização da minha tese de doutoramento.

O livro Contesting the Global Development of Sustainable and Inclusive Education. Education Reform and the Challenges of Neoliberal Globalization é lançado, ironicamente, em plena pandemia da COVID-19. Não que este facto fosse relevante à obra, mas, na verdade, o contexto atual coloca-a, mais ainda, no centro do debate da construção social das políticas públicas por nos emprestar múltiplas lentes de análise social, educacional e cultural face à situação da humanidade, numa era de desenvolvimento global onde proliferam populismos modernos e o incremento de movimentos autoritários e xenófobos.

O livro é o resultado de três décadas de trabalho científico e académico no campo das ciências sociais e da educação, com destaque para o campo da sociologia da educação e da educação comparada, ancorado criticamente em múltiplas redes nacionais e internacionais onde o autor assumiu posições de destaque e de coordenação. Nascido nos Açores (llha do Faial), António Teodoro é Professor Catedrático na Universidade Lusófona de Humanidades e Tecnologias (Lisboa), onde é o diretor do Centro de Estudos Interdisciplinares em Educação e Desenvolvimento (CeiED, Unidade de I\&D financiada pela Fundação para a Ciência e Tecnologia (FCT)), bem como do Instituto de Educação e editor e fundador da Revista Lusófona de Educação. Da sua história de vida, e, sobretudo, daquela que se narra a partir das suas representações profissionais, destaco o facto de ter sido o primeiro Secretário-Geral da Federação Nacional dos Professores (FENPROF) entre 1983 e 1994 o que o viria a implicar em redes sindicais internacionais como o European Board of World Confederation of 
Organizations of the Teaching Profession (WCOTP) e o European Trade Union Committee for Education (ETUCE), e mais tarde, participante na constituição da International Education (IE).

António Teodoro desempenhou funções de Inspetor-Chefe do Ensino Primário (1974-1975), foi membro do Conselho Nacional de Educação (1988-1994), Assessor do Conselho de Ministros da Educação, Ciência, Cultura e Emprego (1995-1999) e cofundador do Instituto Paulo Freire em Portugal. Foi ainda, entre 2006 e 2014, membro do Conselho de Administração e vice-presidente do Comité de Investigação em Sociologia da Educação da International Sociological Association (ISA). É fundador e presidente da Secção de Educação Comparada da Sociedade Portuguesa de Ciências da Educação (SPCE-SEC) e membro-geral da Comissão Executiva e presidente da Comissão Constitucional Permanente do Conselho Mundial das Sociedades de Educação Comparada (World Council of Comparative Education Societies, WCCES).

A relevância destes episódios de vida, pertencentes a um mosaico ainda mais complexo e rico de experiências, são relevantes ao leitor, pois a obra que se apresenta, também é reflexo deste percurso de vida e tal como situado anteriormente, das redes de trabalho e das comunidades de aprendizagem que possibilitaram criar, desenvolver e aprofundar o quadro conceptual, teórico e epistemológico que fundamenta a posição do autor face à construção das políticas públicas no quadro neoliberal de uma globalização de baixa intensidade, enquanto processo de regulação transnacional. Das redes de investigadores e das diversas comunidades de aprendizagem por onde passou António Teodoro destaca-se, por exemplo, a Rede Ibero-americana de Investigação em Políticas de Educação (RIAIPE), cujo objetivo pretendeu mapear as políticas públicas de educação no espaço ibero-americano, a partir de um referencial teórico e analítico que privilegiasse a inclusão social e a equidade educativa.

Atrevo-me a afirmar que no livro há resquícios de uma certa açorianidade, transposta para a sociedade global como uma reivindicação anticentralista, enquanto reflexão e ação críticas face ao capitalismo global na esteira de P. Freire, H. Arendt, I. Wallerstein, N. Chomsky, P. Bourdieu, B. Sousa Santos, M. Castells, A. Giddens, M. Young, entre outros. Quanto mais nos apropriamos dos conceitos abordados no livro mais nos conscientizamos para o impacto de uma Agenda Globalmente Estruturada para a Educação (AGEE) entendida por R. Dale (2004, p. 426) como um conjunto de "forças económicas operando supra e transnacionalmente para romper, ou ultrapassar, as fronteiras nacionais, ao mesmo tempo que reconstroem as relações entre as nações", sendo a globalização construída e ampliada na base de atividades económicas, políticas e culturais.

O livro é um claro manifesto à importância da partilha do conhecimento, da sua disseminação como fonte de poder e de contra-argumentação. É um grito de liberdade intelectual, social e política, na medida em que se desvela na consistência de 
um quadro teórico-prático de excelência, mas que não se mitifica, bem pelo contrário, abre espaço a outras reflexões, convergentes e/ou divergentes, sobre as ciências sociais, em particular as do domínio da educação que se têm posicionado na alçada do neoliberalismo, enquanto expressão hegemónica da globalização, como paliativo das doenças dos Estados. O livro enaltece a fala de M. Cesariny em You are welcome to Elsinore quando diz "Entre nós e as palavras, os emparedados / e entre nós e as palavras, o nosso dever falar."

Do livro destaca-se, num primeiro momento, o valioso prefácio de Carlos Alberto Torres. O texto de Torres não é um artigo de circunstância. Muito pelo contrário! É um ensaio poderoso e atual sobre a cidadania global e que enquadra as tendências sociopolíticas globais e os seus condicionalismos na construção das políticas públicas no campo da educação e da cidadania global, pelo que se apresenta como um convite à leitura necessária da obra de Teodoro, que aborda esta dimensão e a amplia, na base de resultados de investigação e de um arcaboiço teórico de relevo.

Para Torres, o futuro apresenta-se na encruzilhada de dois discursos dominantes: um, que pretende recuperar os ideais do lluminismo, como a liberdade a tolerância e a fraternidade, o valor da investigação científica e da racionalidade capaz de acoIher a humanidade nas suas idiossincrasias e, outro, saudosista de um passado de pequenas elites dominantes dos poderes político, económico e cultural. $\mathrm{O}$ ensaio de Torres apresenta e desenvolve o conceito de educação para a cidadania global, os seus domínios e competências, e introduz as proposições básicas dos bens comuns globais: o planeta, a paz mundial, as pessoas. O ensaio de Torres reforça, tal como a obra de Teodoro, a importância do triângulo, educação - cidadania global - justiça social e cognitiva, e a sua ação poderosa na construção e compreensão, num modelo bottom-up, das políticas públicas.

O livro de António Teodoro estrutura-se, além do prefácio e da introdução - que reforça a importância das redes de investigação e das comunidades de aprendizagem para o aprofundamento da ciência e do desenvolvimento e a disseminação do conhecimento - numa antropologia freiriana que reconhece homens e mulheres na sua curiosidade (de senso comum e epistemológica), incompletude e conectividade e que trespassa todos os seis capítulos que o constituem. Sendo certo que se dirige a académicos e investigadores interessados na análise e compreensão da educação num contexto globalizado, também é verdade que se apresenta como uma referência completa sobre tais fenómenos aos estudantes da formação graduada e pós-graduada. Em ambos os públicos e tal como situa P. Freire em Política e Educação (1993, p.97), o livro convida-nos a entender que "a História como possibilidade reconhece a importância da decisão como ato que implica ruptura, a importância da consciência e da subjetividade, da intervenção crítica dos seres humanos na reconstrução do mundo." (p. 97). 
O primeiro capítulo intitulado - Educação em tempos de mudança. Problemas Críticos e Agendas de Investigação - decorre, sobretudo, do enquadramento teórico, que cruza fronteiras disciplinares e que sustentou a candidatura a um projeto apresentado à União Europeia e que sistematizando algumas questões de natureza prospetiva que se colocam à educação na Europa, num horizonte de trinta anos. Este capítulo apresenta uma análise detalhada de doze problemas críticos que se colocam face à crise da escola e dos sistemas de educação e ensino, como por exemplo: o esgotamento do modelo de escolarização; inflação escolar ou armadilha de oportunidades; teorias e práticas de aprendizagem; a produção de conhecimento e o currículo escolar; educação de adultos; formação de professores e o pouco impacto dos estudos do cérebro nas políticas educativas. É um precioso contributo à compreensão do desenvolvimento dos sistemas educativos a partir de diferentes níveis de análise - supranacional, nacional, institucional e individual - que demostram que o global e o local estão em transformação e que nesse cenário se perfilam formas complexas de reconstrução da educação que não se circunscrevem, meramente, às fronteiras, cada vez mais híbridas dos Estados. O capítulo termina com a apresentação de seis agendas de investigação que se poderão constituir como um valioso contributo à superação da crise das políticas públicas de educação submersas no discurso neoliberal da governança. Essas agendas de investigação são: aprendizagem ao longo da vida e sociedade do conhecimento; cidadania global e currículo escolar; educação e empregabilidade; estudos do cérebro e aprendizagem; o mal-estar dos atores: jovens e professores; alternativas para a educação institucionalizada.

Os capítulos dois e três do livro reúnem textos que têm estado no centro do trabalho científico do autor, desde o ano de 2009, tendo sido objeto das suas Provas de Agregação. Relativamente ao capítulo dois, o autor centra-se nos processos de globalização, sobretudo no neoliberalismo como a sua expressão hegemónica. O capítulo dois discorre sobre o conceito de globalização e mundialização, a partir de W. Mignolo, bem como adentra nos estudos de A. Giddens, D. Held, A. McGrew, D. Glodblatt e J. Perraton sobre o conceito de globalização ou globalizações informando sobre tipologias ou tendências relativas à globalização, e avança com uma proposta do sociólogo português B. Sousa Santos assente em quatro modos de regulação: localismo globalizado, globalismo localizado, cosmopolitismo e património comum da humanidade. Destaco ainda neste capítulo o enquadramento que é dado ao conceito de neoliberalismo como expressão hegemónica da globalização, sobretudo à narrativa que o autor constrói a partir dos trabalhos de D. Harvey, O. lanni, A. Ong de onde se destacam conceitos como o de classe, Estado e nova ordem social.

Relativamente ao capítulo três, a análise aos processos de globalização iniciada no capítulo anterior é intensificada enquadrando e desenvolvendo os novos modos de regulação transnacional das políticas educativas, com especial destaque para o conceito 
de governança. Como já referido anteriormente, o conceito de governança assume-se para o autor como o modo de regulação por excelência do neoliberalismo. O texto aborda o desmoronamento da legitimidade do Estado e a assunção de fronteiras híbridas penetradas pela globalização neoliberal através dos mandatos de grandes organizações internacionais como a Organização para a Cooperação e Desenvolvimento Económico, o Banco Mundial ou o Fundo Monetário Internacional, por exemplo. O texto, num segundo momento, é revelador do impacto dos números e/ ou indicadores na gestão e organização das agendas dos governos e, consequentemente, das políticas públicas com especial enfoque nas políticas educativas e na administração educacional. Neste contexto, o autor enquadra o papel do Relatório - Education at a Glance, da OCDE, que tem sido exímio na regulação da agenda educativa mundial, bem como, e da mesma Organização, os programas PISA (Programa Internacional de Avaliação de Alunos), PIRLS (Programa Internacional de Avaliação da Literacia de Leitura), TIMSS (Avaliação Internacional do Desempenho dos Alunos em Matemática e Ciências), TALIS (Inquérito Internacional sobre o Ensino e Aprendizagem) e os indicadores para os sistemas educativos decorrentes do trabalho do Centro para a Investigação e Inovação no Ensino (CERI - OCDE). O capítulo três permite-nos obter um entendimento mais amplo sobre os processos de normalização, decisão e/ou regulação da política educativa em tempos híbridos de globalizações, a partir dos quais "os indicadores e comparações são mobilizados, principalmente, para pôr certos problemas na agenda política." (Barroso \& Afonso, 2011, p. 21).

No capítulo quatro, o autor aprofunda a análise, entretanto iniciada nos capítulos dois e três, sobre o espaço e o tempo da OCDE, como estrutura de coordenação internacional na regulação das políticas educativas. Estamos perante um texto que analisa criticamente o Movimento Global de Reforma da Educação (GERM - OCDE) e, de forma ímpar, o livro de Andreas Schleicher, World Class: How to Build a 21st-Century School System (2018).

Neste capítulo, debate-se a partir de P. Sahlberg, entre outros, o poder de uma ideologia a que A. Teodoro conceptualiza como novo ocedeismo (do inglês oecdism), claramente ancorada nos princípios neotayloristas da eficácia, da eficiência, da competitividade, da previsibilidade e do controlo digital, mascarados no discurso epopeico da OCDE acerca das competências, conhecimentos, capacidades e atitudes que decorrerem dos processos de ensino-aprendizagem. O ocedeismo é narcisista e "O sujeito narcísico não percebe o mundo a não ser sob a forma de matizes de si mesmo." (Han, 2018, p. 31), convertendo o outro em extensão (Freire, 1977) de si mesmo, coisificando-o, normalizando-o, retirando-Ihe a capacidade de se transformar em agente de mudança. Esta narrativa, com o enquadramento que nos é trazido pelo autor, surge despojada dos pilares da história moderna da pedagogia e do pensamento, por exemplo, de A. Ferrière, J. Piaget, J. Dewey, C. Freinet e P. Freire. O capítulo alerta-nos 
para os perigos de uma McDonaldização da sociedade (G. Ritzer) e em particular da educação (T. Tadeu da Silva; J. A. Pacheco; M. Apple, et al), assente num processo de normalização das políticas educativas globais, na lógica do mercado e do gerencialismo travestidos de accountability e transparency.

O autor ainda discute neste capítulo e a partir de P. Sahlberg as cinco principais características comuns das políticas educativas geradas pelo Movimento Global de Reforma da Educação (GERM - OCDE): mecanismos de competição; padronização do ensino e aprendizagem nas escolas; ascensão de um currículo básico comum (cuja matriz valorativa está no Programa PISA); generalização e/ou empréstimo de modelos de mudança assentes na nova gestão pública; políticas de responsabilidade baseadas em teste.

No capítulo cinco e, em grande parte a partir do trabalho desenvolvido na RIAIPE, o autor centra a sua análise no papel desempenhado pelas instituições de ensino superior na contestação dos modelos neoliberais, o seu fracasso no plano económico, mas normalizado como política cultural que teima em dividir a humanidade em dois eixos distintos: o norte (enquanto centro de poder) e o sul (permanentemente colonizado, portanto, subalterno). Neste cenário, o autor questiona o papel do ensino superior na construção de processos de justiça social e cognitiva, como também os seus futuros possíveis capazes de valorizar outras racionalidades promotoras da dimensão humana do desenvolvimento. Não nos esqueçamos que "no inferno do idêntico, os homens não são mais do que bonecos manobrados à distância” (Han, 2018, p. 18).

O capítulo cinco enquadra, ainda, as principais características que determinaram a reorganização do ensino superior na Europa, nomeadamente, o Processo de Bolonha e a Crise das Dívidas Soberanas, bem como na américa latina, com um ensino superior dependente da expansão do neoliberalismo e do conservadorismo e em alguns casos da regressão democrática, de preservação de privilégios e interesses particulares. Por fim, A. Teodoro finaliza o capítulo com a apresentação de nove propostas que se perspetivam como os pilares de uma universidade cidadã. Ficamos perante um conjunto de inéditos viáveis (P. Freire) que convidam o leitor e, em particular, aqueles que estão próximos da Academia a repensar o seu papel na ação glocal, num posicionamento tanto democrático como inclusivo, que assume o conhecimento poderoso (M. Young) para todos.

O último capítulo do livro, o sexto, portanto, é um texto que realça o legado de P. Freire na ação política e profissional do autor, na medida em que recupera o seu discurso sobre a história como condicionalismo e não como um determinismo apriorístico e ideológico, que nos fada e determina enquanto seres humanos, que nos desnuda de identidade, de cultura, de tempo e de espaço. A pergunta que dá título ao capítulo - É possível uma alternativa às questões de política educativa derivada da globalização neoliberal? - convida-nos a desvelar outras formas possíveis de construir as políticas 
públicas de educação. Os capítulos anteriores prepararam o leitor para este ponto de encontro. Somos confrontados com a nossa imagem, uma espécie de retorno do ator (A. Touraine) que nos convida a transformar a nossa forma de pensar sobre as mudanças sociais em curso. Esta possibilidade de pensar de outro modo (A. Touraine) permite-nos ajuizar, com maior clareza, o nosso papel na educação na era planetária (E. Morin). Neste sentido, A. Teodoro partilhando do pensamento de U. Beck, J. Habermas, B. Sousa Santos, A. Nóvoa, R. Dale e G. Therborn, apresenta três possíveis pontos de partida para a construção de uma agenda para a educação, capaz de gerar novos sentidos comuns mobilizadores da esperança e da ação humana, onde a Europa se poderá posicionar como um centro normativo de relevo mundial.

Por fim, como conclusão do livro, o autor disserta sobre a utopia da educação como projeto de justiça social e cognitiva. Estamos perante um curto ensaio do autor que questiona, hoje em dia, o legado da Pedagogia do Oprimido (P. Freire) e os seus inéditos viáveis, ou utopísticas (I. Wallerstein). A visão de P. Freire sobre a humanidade é justaposta ao pensamento de $\mathrm{H}$. Arendt sobre a condição humana e o resultado é a exaltação da humanidade, dos seus direitos fundamentais e o seu posicionamento na construção das políticas educativas contemporâneas. O texto resgata a visão do sonho de M. Luther King e conduz-nos para a existência de um outro mundo possível, como construção e/ou movimento global, que se desvele na base de três pilares essenciais, e que retomo: o planeta, as pessoas, a paz mundial (C. A. Torres).

Como assinalei no decorrer deste texto, o livro é um manifesto educativo que nos convoca para a ação necessária de transformação da cara da escola (P. Freire), coIonizada no discurso do neoliberalismo. A narrativa da globalização neoliberal faliu. É urgente repensar e refletir sobre outros cenários possíveis à nossa vida nesta casa comum a que chamamos Terra, pelo que subscrevo as palavras de Harari (2018, p. 302) quando afirma que: "para conseguirmos acompanhar o ritmo do mundo em 2050, será preciso não só inventarmos novas ideias e novos produtos, mas sobretudo reinventarmo-nos a nós mesmos uma e outra vez". Estamos perante uma obra que é crítica à miopia provocada pelas ideologias dominantes, pela sua capacidade de amaciar e de nos subalternizar no discurso da governança, da sua eficiência e eficácia. É um livro que nos confronta com a grande questão: O que nos une enquanto seres humanos? Da sua leitura, sejamos capazes de analisar e aprofundar quais os contributos da educação para a construção de um mundo capaz de superar as suas desigualdades e aspirar os ideais de paz e de felicidade do lluminismo. Um mundo capaz de recuperar a sua hospitalidade (B-C. Han). 


\section{Referências}

Barroso, J., \& Afonso, N. (2011). Introdução. In J. Barroso, \& N. Afonso, Políticas Educativas. Mobilização de conhecimentos e modos de regulação. V. N. Gaia: Fundação Manuel Leão.

Dale, R. (2004). Globalização e educação: demonstrando a existência de uma "Cultura Educacional Mundial Comum" ou localizando uma "Agenda Globalmente Estruturada para a Educação"? Educação \& Sociedade, 25(87), 423-460. https://doi.org/10.1590/S0101-73302004000200007

Freire, P. (1977). Extensão ou comunicação? São Paulo: Paz e Terra.

Freire, P. (1993). Política e Educação. São Paulo: Cortez Editora.

Freire, P. (2018). Pedagogia do Oprimido. Porto: Edições Afrontamento.

Han, B-C. (2018). A Expulsão do Outro. Lisboa: Relógio D’Água.

Harari, Y. N. (2018). 21 Lições para o Século XXI. Amadora: Elsinore

Nuno Fraga

Doutor em Educação

Professor na Universidade da Madeira Coordenador Científico do Centro de Investigação em Educação (CIE-UMa)

Email:nfraga@uma.pt ORCID: https://orcid.org/0000-0002-3382-6357 
Revista Lusófona de Educação

\section{teses \\ e dissertações}
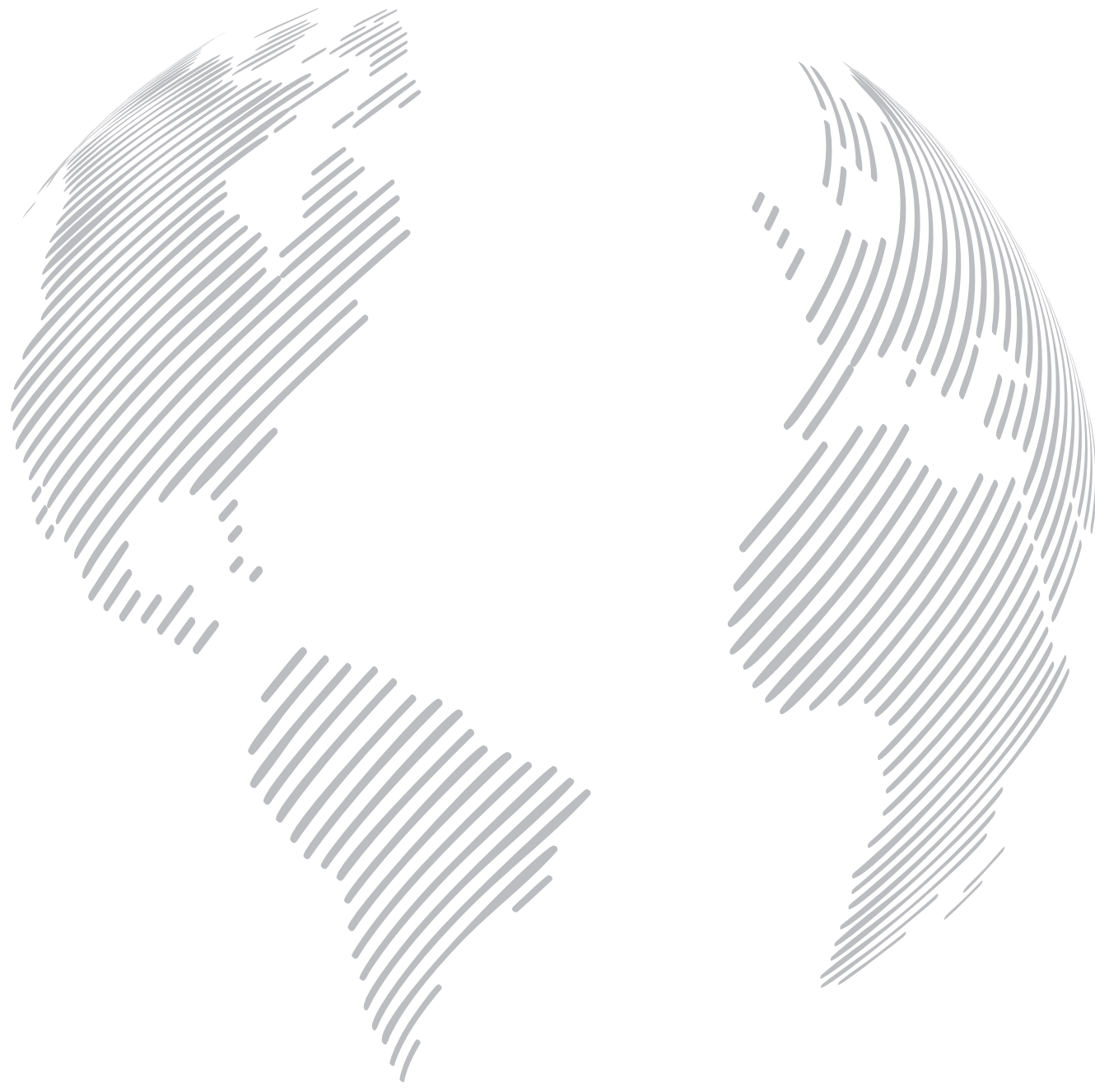
